\title{
APROXIMACIONES AL CONCEPTO DE CONOCIMIENTO EN LOS DISCURSOS HISTÓRICOS A PARTIR DE LOS APORTES DE TEUN VAN DIJK
}

\author{
Una mentira que te haga feliz \\ vale más que una verdad que te amargue la vida.
}

Ricardo Arjona

¿Qué son los discursos sino versiones de la verdad? ¿Qué es la Historia, sino una construcción en la que queremos vernos con orgullo? ¿Hasta qué punto es válida esta construcción? ¿Dónde comienza la Historia y termina la memoria selectiva? ¿Será la Historia que aprendemos, mentiras que nos hacen felices? ¿Dónde está la verdad de la Historia? ¿Podré yo o podrá alguien responder estas preguntas?

Este artículo completa una serie de tres que en el marco de un estudio independiente realicé como parte de mi formación en el doctorado en ciencias de la educación. Teun Van Dijk y sus producciones relacionadas con el Análisis Crítico del Discurso (ACD) han llegado a constituirse, luego de revisar otros teóricos en el área, en las más importantes y pertinentes para dar base a mi tesis doctoral.

La aproximación minuciosa que desde su particular perspectiva hace a las implicaciones del discurso desde el punto de vista ideológico, sirven de andamiaje a lo que intento demostrar en mi tesis. La enseñanza de la Historia como práctica pedagógica está revestida de particulares atributos si tomamos en cuenta que a través de ella se configura una concepción particular de país, héroes, historia, papel de los colectivos, etc.

Van Dijk describe a los discursos como armas potenciales, les confiere intencionalidad. Así como un arma puede usarse para el bien también puede hacerse para el mal; el problema en este caso es discriminar qué está bien y qué está mal en el uso del discurso pedagógico en la enseñanza de la Historia.

Defino este constructo como "discurso pedagógico" porque si se analiza detenidamente el alumno que cursa sus estudios de bachillerato es bombardeado de manera consciente o no por variados discursos. Dentro del aula y fuera de ella, en el texto y fuera de él, por el docente como facilitador se construyen supuestos y cogniciones sociales llegando a formarse una red de discursos que juntos delinean un específico estudiante-tipo, con unas competencias esperadas y asumidas. 
En este artículo en particular, quiero detenerme en aquellos elementos que para mi trabajo dan luces en relación a la definición de ideología dentro del discurso pedagógico. Es, de esta forma, una aproximación sin prejuicio a la definición de aquellos elementos que a decir de Van Dijk configuran ideología en los discursos.

Es pertinente, en principio, establecer que estoy consciente de que no existe discurso sin ideología y de que, cuando se escogen palabras, se describen hechos, no se hace desde la ingenuidad, algo se persigue, algo quiere embalsamarse para la posteridad sepultándolo en la atemporalidad del texto.

De esta forma, no se trata de legitimar o deslegitimar ideologías y posturas personales frente a la Historia, frente a la cual siempre se tendrá alguna; se trata más bien de alertar sobre el contenido que los discursos tienen y de que quien se aproxima a ellos lea, como en algunos productos, la advertencia de que su contenido tendrá un efecto en él.

En artículos anteriores a éste he revisado la obra de Van Dijk y con sus aportes he ido construyendo instrumentos de análisis cualitativo para textos y discursos orales. Obras como Racismo y discurso de élites(1993) e Ideología y discurso (2003), entre otros, se me presentan pedagogos en el proceso de ACD, es decir, enseñan cómo analizar los discursos, presentan proyectos culminados, comparten experiencias prácticas.

En este texto en particular, Ideología (2006), Van Dijk se me dibuja, teórico, arrojado, sentando cátedra desde su experiencia. Como no lo leí antes, en este texto Van Dijk redefine constructos, les da nueva semántica, les otorga significados que ha ido descubriendo desde su práctica investigativa. Ideología, creencia, juicios, opiniones son algunos de los conceptos que ya desde su sólido prestigio y sin temor a la diatriba se embarca en definir.

Escribiendo la Historia de la ideología, agrega y enriquece a estas definiciones con lo que a su juicio les dan pertinencia en este contexto. Desde mi posición de aspirante a doctora en ciencias de la educación y a lo largo de mi carrera he aprendido que las ideas, pertenezcan éstas a una corriente en particular, pueden sedimentarse, al establecerse como corrientes oficiales, colocan restricciones a lo que puede decirse, escribirse u opinarse.

Si nuestras teorías o ideas no suenan en la misma escala que las de la academia, son censuradas y a través de sutiles mecanismos, silenciadas. Lo único que legitima, desde mi humilde opinión, cualquier idea, es su continua renovación y revisión; es por eso que me confieso seguidora de un investigador que no se detiene, que no se la cree, que se cuestiona y que lo cuestiona todo. 
En este texto Van Dijk le "corrige la plana" a los grandes, práctica que no debería ruborizar a nadie porque, si al final del cuestionamiento, la idea queda en pie, qué mejor forma de demostrar su validez, pero si no era así, si se trataba de una verdad oficial que con la dictadura de los pizarrones se erosionó, más vale ahora que después el haberlo descubierto.

Los conjuntos estables de ideas, también llamados teorías, se vuelven tan estables que no hay quien los cuestione. Se vuelven tan sólidos que no se les puede tocar porque se rompen. Si ya no son verdades, son mentiras, mentiras de autodefensa. La Historia autodefensa, la ideología de autodefensa, la teoría de autodefensa.

El buen investigador no teme el cuestionamiento al otro, pero tampoco a él mismo. De esta forma Van Dijk deberá estar preparado para que alguien lo adverse, para que sea a él a quien se le corrija la plana, porque es desde la práctica que las teorías se confirman, es desde y para la práctica que tienen sentido. Aproximarnos desde esta perspectiva a la definición de estas categorías redefinidas por Van Dijk, pero en este caso en el discurso pedagógico en la enseñanza de la Historia, es lo que intentaré en estas líneas.

Así, desde una lectura pragmática de la obra de Van Dijk comenzaré por definir conocimiento. Sin ánimo de hacer teoría del conocimiento, Van Dijk (2006) lo define como el producto del pensamiento que se considera verdadero (p. 35). El conocimiento en la ciencia histórica, así como en la epistemología, ha transcurrido por etapas y fases donde el mismo está revestido de diferentes atributos.

En los principios de la historia más como práctica retórica que como ciencia, cuando de lo que se trataba era de un ejercicio eminentemente anecdótico, lleno de especulaciones y leyendas emocionantes, conocimiento era aquello registrado por estas narraciones fantásticas, era verdad el pasado narrado y descrito de esa forma, era verdad porque era la única que se conocía.

Heródoto, llamado padre de la Historia, escribió su obra en dialecto jónico, y más tarde fue dividida por los gramáticos de Alejandría en nueve libros tomando el nombre de las nueve musas de la mitología griega: Calíope, Clío, Talía, Euterpe, Terpsícore, Melpómene, Erato, Urania y Polimnia. Todas ellas, hijas de Zeus y Mnemoside. Musas que eran consideradas como las protectoras de las artes, la memoria y la astronomía. Sin duda alguna reconstrucción del pasado desde y para occidente.

Su obra se llamó Historiae, cuyo nombre deriva de la palabra griega investigación o búsqueda. Aunque no solo se dedicó a registrar lo que le decían, sino que fue un incansable viajero que se recorrió todo el Egipto, la Magna Grecia, Anatolia y gran parte del Imperio Persa para 
poder interpretar con sus propios ojos la realidad y así escribirla. Es el primero en ordenar de forma racional los hechos, al menos desde la razón conocida, con la cronología y la geografía del entorno que estudiaba.

La primera frase de su obra era Historíes apódexis, que significa "exposición de las investigaciones", revistiendo su ejercicio de un anhelo de cientificidad. Su principal obra histórica fue Las Guerras Médicas o, lo que es lo mismo, la unión de las polis contra el Imperio Persa (los medos); en ellas fue tachado de fantasioso y exagerado por autores griegos como Etesias, Isócrates o Plutarco, opiniones que se mantuvieron hasta los descubrimientos arqueológicos del antiguo oriente en el siglo XIX, en donde se demostró la veracidad de gran parte de su obra.

Por otra parte, Heródoto sólo hablaba el griego y siempre tuvo necesidad de guías y traductores, lo que pudo influir en la narración de acontecimientos que él no pudo ver y que le llevaron sin duda a confiar en lo que le decían los nativos o a registrar lo que le decían confiando en su subjetiva interpretación.

¿Qué es conocimiento histórico entonces? Con el positivismo como revolución de la ciencia y el cuestionamiento de todo saber que no fuera comprobable, los ojos de la Historia miran hacia otro lugar.

El conocimiento había que demostrarlo, no sólo creerlo. Se trataba de una historia basada en el análisis crítico de las fuentes -documentos principalmente- de carácter narrativo, contenido político y con un componente idealista muy pronunciado que consideraba a las ideas, encarnadas en hombres o instituciones como las raíces últimas los procesos históricos.

Frente a este tipo de historia, "historicista" en la terminología alemana de la época, a mediados del siglo XIX surge un nuevo modelo, la historia "positivista", fundamentada en fuentes auténticas, depuradas por la crítica, y diferente de la anterior por el estilo, el contenido y la base filosófica. Se trata de una historia más analítica que narrativa, que pretendía abarcar el comportamiento humano en toda su extensión, y no sólo lo político, y que trataba de encontrar la explicación última de los hechos en la misma naturaleza de las cosas y no en ningún tipo de realidad trascendental.

Quedaba atrás, al menos en esa corriente oficial, esa especie de historia sagrada, de la que se aprende y no se cuestiona, digo que al menos de la corriente oficial, porque nunca he sido partidaria de estudiar a las corrientes como realidades arraigadas a momentos históricos concretos; creo que hay románticos de la historia hoy en pleno siglo XXI, hay quienes siguen haciendo historia literaria, narrada como cuento de arrullo, y también existen hoy quienes sólo consideran 
historia a los hechos que son comprobables y atrapados en tubos de ensayo y líneas del tiempo, desconociendo también que hay historias que no registran los diarios, ni libros de texto y no por eso duelen menos.

¿Y si las fuentes no cuentan la verdad? ¿Y si quien escribió lo que está registrado en ella escribía desde y para una ideología? ¿Qué conocemos entonces? Ya sabemos que la verdad no está en la anécdota que emociona y de la que no hay certeza, pero, ¿y si tampoco está en la fecha, o en el documento forjado, en la verdad a medias, que se escribe para justificar abusos y genocidios?

Tomemos como ejemplo la famosa Guerra de las Galias. La Guerra de las Galias fue una serie de ocho campañas (del 58 al 51 AC), llevadas a cabo por las legiones romanas al mando de Julio César contra los pueblos galos, y que permitieron a la República Romana adueñarse de todo el territorio de la Galia y partes de Germania.

Esta reconstrucción es Historia según el positivismo porque está registrado en fuentes, pero escritas por el propio Julio César. ¿Qué nos garantiza su objetividad al registrar los hechos? El conocimiento como información cierta tampoco se encuentra por completo en esa aproximación a la Historia ya que las fuentes pudieron, pueden y podrán ser estructuradas para dejar bien parados a unos y otros.

¿Cuántas crónicas son escritas bajo este paradigma? La dialéctica del conocimiento generó mecanismos de autodefensa e identificó lo limitado e irreal de esta visión de la Historia y gesta el materialismo histórico. Reflexión surgida dentro del marxismo como filosofía pero que planteaba la interpretación de la historia desde una nueva perspectiva: el materialismo.

Como reflexión del hecho histórico el marxismo sostiene que la historia es consecuencia del desarrollo dialéctico de la infraestructura económico-social, causa de los hechos y motor de la evolución de la humanidad, de esta forma, la historia ya no es sólo una fotografía que se registra en el documento sino una realidad dinámica, es un proceso continuo en el que las contradicciones de hoy generarán los cambios mañana. Las relaciones económicas dan origen a las clases sociales y a la infraestructura que determina la formación de una superestructura, integrada por la ética, la cultura, la religión y el ordenamiento jurídico.

El entorno define al hombre, según el materialismo histórico, y desde esta afirmación, garantizando un entorno de justicia y equidad, se resuelve el problema de la lucha de clases (Fernández, 2004). Esto es así porque según Marx la ideología de una época es la de la clase dominante, hecho que también apunta a que la concepción del conocimiento, la ciencia y la verdad pueden ser también producto de 
esquemas de esa clase dominante, en las aulas, en el estado, en la sociedad.

De esta manera, la burguesía se adueña del poder; desde su condición de propietaria de los medios de producción (infraestructura) crea desde ellos un sentido de la ética, una cultura y un ordenamiento jurídico (superestructura) que forman una conciencia favorable al sistema. Si entendemos la educación como parte de ese tinglado cultural, tiene aún mayor sentido el plantearse que todos los contenidos respondan a visiones concretas e intencionadas de la realidad.

En el curso de su desarrollo, las fuerzas productivas de la sociedad entran en contradicción con las relaciones de producción existentes, y esas relaciones se convierten en trabas de las relaciones productivas. Se abre entonces una era de revolución social, que afecta a la estructura ideológica, de forma que los hombres adquieren conciencia del conflicto.

Este conflicto planteado por Marx, se da desde mi perspectiva en todas las áreas del saber. La Historia evoluciona, asumiendo la evolución como cambio, no necesariamente su perfeccionamiento; lo hacen las otras ciencias y las artes. Se dispara la rebelión de los oprimidos a decir de Marx y en su emancipación se generan nuevas formas de ver la realidad. ¿Qué hacemos entonces? ¿Ahora la verdad y el conocimiento histórico están teñidos por la visión del materialismo histórico y como quien empieza un libro nuevo lo anterior no existe? ¿No es necesaria la anécdota emocionante? ¿No es pertinente la fecha y el documento que comprueba la existencia de los hechos? ¿Son ahora esas contradicciones sociales en las que el hombre se mueve por necesidades económicas las que nos permitirán interpretar y escribir la historia de los pueblos?

Así podría continuar paseándome por las diferentes escuelas metodológicas que exigieron del conocimiento histórico nuevos atributos y condiciones. La Escuela de los Annales de Marc Bloch (1997) y Lucien Febvre (1971) hacen aportaciones de mayor complejidad al análisis de la Historia permitiendo su abordaje desde la interdisciplinariedad.

La idea no es hacer un recuento algo tedioso para quien no comparte esta pasión, pero la conclusión a la que pretendo llegar es que cuando Van Dijk define el conocimiento como el producto de lo que se considera verdadero, en el caso de la historia y en cada uno de sus respectivos contextos, todas estas escuelas y las que seguirán estarán convencidos de que son ellos quienes generan conocimiento y en gran medida lo hacen, al añadir elementos nuevos a la reflexión.

El conocimiento de la Historia fundamenta creencias a las que Van Dijk (2006:37) define como ladrillos del edificio de la mente, y yo añado, 
ladrillos en la construcción de ciudadanos. Al asumir un determinado discurso, me atrevería a afirmar que también se asumen valoraciones de los hechos registrados. Las diferentes escuelas metodológicas y sus discursos históricos van acuñando expresiones, calificativos, epítetos con los que se va asociando a personajes. El llustre Americano, calificativo otorgado a Guzmán Blanco, presidente de Venezuela quien nació en Caracas el 28 de febrero de 1829 y murió en París (Francia) el 28 de julio de 1899. Hijo del político Antonio Leocadio Guzmán, fundador del Partido Liberal, y de Carlota Blanco Jerez de Aristeguieta, emparentada con la familia de Simón Bolívar.

Simón Bolívar, que recibe el calificativo de mágico adelantado; Cipriano Castro, quien fue calificado por sus abusos, se convirtió en dictador y se hizo acreedor de apodos como El Cabito, El Mono Trágico, El Capitán Tricófero, etc. Cómo validar estos calificativos; habría que estudiar los contextos en los cuales fueron generados y por quienes ya que sin duda todos estos historiadores establecieron calificativos que en los textos de historia y en los discursos de los docentes se repiten como verdades sin cuestionar.

Se plantea lo que Van Dijk (2006) denomina la disyuntiva entre epísteme y doxa (p. 36), la necesidad de definir y diferenciar ciencia y creencia. Lo que se conoce y de lo que se tiene certidumbre. ¿Lo problemático con la Historia denominada ciencia social es que es ciencia y que es creencia, si la línea divisoria y los efectos de la ideología del momento son tan difíciles de distinguir? ¿Cuánto de emoción no ha podido influir en los diferentes calificativos asignados a hechos o personas?

¿Cómo poder distinguir un genocidio de un proceso civilizatorio?, ¿un golpista de un patriota?, ¿un desequilibrado de un nacionalista?, ¿un amante de su pueblo y un populista? La diferencia la determina la ideología desde la cual el discurso se articula. ¿Qué mueve al historiador? ¿Qué busca? Cuando califica en su discurso con evidente sumisión las acciones de un imperio, cuando se omiten del texto fragmentos e historias que describen a Latinoamérica y su lucha constante y valiente, cuando desde la filosofía y su estudio se marginan producciones teóricas de latinoamericanos para latinoamericanos.

Cuando se silencia a Rigoberto Lanz (2007), a José Vasconcelos (1988), a Leopoldo Zea (2000) al excluirlo del estudio de la filosofía occidental, ¿qué puede buscarse?, ¿es una omisión inocente? ¿O es un olvido que busca apuntalar la dependencia cultural de nuestros pueblos a los lineamientos de Occidente?

Las emociones se vuelven evaluaciones y las evaluaciones conocimiento aprendido en las escuelas. Hemos aprendido que la mujer no existe en la Historia de Venezuela, que no tuvo peso alguno en las 
luchas preindependentistas, salvo dos o tres honrosos casos que lo que hacen es confirmar la regla, no existe la mujer. ¿Qué le dice eso a un joven que estudia historia de Venezuela? ¿Qué supuestos se instalan en su mente? ¿Qué nos dice de los negros? ¿De los indígenas? Son tan complejos y tan residuales que se vuelven pensamiento "lógico", sentido común al decir de Van Dijk. ¿Y cómo hacer cuando estos pensamientos, que hacen supuestos verdaderos, conforman creencias, éstas son cimentadas por emociones que se establecen como evaluaciones de hechos y acciones? ¿Cómo hacer cuando estas redes han conformado ideologías que definen nuestra identidad como venezolanos?

Van Dijk (2006) define de manera brillante varias categorías para el análisis crítico del discurso como elemento generador de ideologías o al menos categorías que me permitirán en los discursos analizados (docente-texto-alumno) develar algunas de ellas. Al exigir un abordaje necesariamente multidisciplinario donde la antropología, la sociología la lingüística, la psicología y por supuesto la historia tomen partido, estaremos más cerca de desentrañar estas redes discursivas.

Gráficos, morfología, sintaxis, semántica, proposiciones, lo implícito, lo explícito, los actos de habla, las estructuras retóricas, todas ellas unidades necesarias en el análisis de los discursos orales y escritos. Las imágenes que acompañan los textos, reseñas de la llegada de Colón a las costas de la Península de Paria, en la que Colón empuña en su mano una cruz y a sus pies un indígena se arrodilla recostando su rostro sumiso en el regazo del conquistador, por citar una de ellas. ¿Fue ese el papel de los indígenas? ¿Acaso no fueron recios e indómitos? ¿Qué papel cumplen las imágenes religiosas en los textos?

La interacción que se genera con el estudiante, si es el caso, ¿desde qué perspectiva se plantea? ¿El que lee es incluido en el discurso? ¿Qué papel tiene en él? Todas estas preguntas las he ido formulando y respondiendo en ya seis textos analizados desde los aportes teóricos de Van Dijk, y a estas alturas de la investigación, cuando en diversos escenarios se me pregunta cómo sería ese libro perfecto, qué ideología debería tener, respondo que la mejor ideología serán todas y ninguna, que el docente no está llamado a hacer proselitismo y que no debe perseguir el convencimiento; les digo que el mejor texto serán todos y ninguno, todas las voces y ninguna, un aula donde se discuta con pluralidad y al terminar se respeten las disidencias en la certeza de que sólo en ese diálogo dialéctico se podrá llegar a una verdad consensuada, una donde para todas las historias haya lugar.

Van Dijk es, sin duda, un buscador de la verdad que no se encuentra, de la que sólo vemos el reflejo, siempre cerca, siempre coqueta, pero esquiva. En la enseñanza de la Historia creo yo que pasará lo mismo. Al defender esta tesis, cuando ilusamente crea haberla terminado, la verdad se escapará de mis manos y algún estudioso me corregirá la 
plana; es esa la esperanza de la academia, la humilde búsqueda de la verdad, aunque sabemos que no llegaremos a encontrarla. Sigamos pues a quienes buscan la verdad, desconfiemos de quienes dicen haberla encontrado.

\section{Referencias bibliográficas}

- Bloch, M. (1949). Apología para la historia o el oficio de historiador. París, Cahier des Annales, № 3, Ed. Armand Colin, 1949, 6 ediciones. París, Ed. Armand Colin, 1972, prefacio Georges Duby. París, Ed. Armand Colin, 1993, edición crítica preparada por Etienne Bloch. París, Ed. Armand Colin, edición abreviada, 1997. Traducción en español -en México-: Apología para la historia o el oficio de historiador, México, Instituto Nacional de Antropología e Historia, 1995, 398 p. Luego, nueva edición, México, Instituto Nacional de Antropología e HistoriaFondo de Cultura Económica, 1996, 398 p. Después, traducción de la edición abreviada de 1997, México, Fondo de Cultura Económica, 2001, 181 p.

- Berlin, I. (2003). Karl Marx: su vida y su entorno. Paidós. España.

- Febvre, L. (1971). Combates por la historia. Barcelona: Ariel.

- Fernández Buey, F. (2004). Marx (sin ismos). Barcelona, El Viejo Topo.

- Van Dijk, T. (2006). Ideología. Gedisa Editorial. Argentina. 